\title{
A Reforma Psiquiátrica em Ímola e o tempero brasileiro
}

\author{
The Psychiatric Reform in Imola and the "taste" of Brazilian seasoning
}

\author{
Maria Stella Brandão Goulart \\ Universidade Federal de Minas Gerais \\ Brasil \\ Ernesto Venturini \\ Azienda Sanitaria di Imola, Fondazione Franca e Franco Basaglia \\ Itália \\ Adelaide Lucimar Fonseca Chaves \\ Brasil
}

\begin{abstract}
Resumo
Este artigo aborda o processo de desinstitucionalização no contexto da reforma psiquiátrica ocorrido em Ímola a partir da narrativa de brasileiros e brasileiras que participaram de seu cotidiano ao longo dos anos noventa. A pesquisa que sustenta o artigo procurou delinear as conexões entre Brasil e Itália no que concerne às contribuições no conjunto de ações que resultaram no fechamento dos manicômios e na constituição dos serviços territoriais (centros de saúde mental, centros diurnos) e de associações e cooperativas que sustentaram projetos de inclusão social. A metodologia utilizada nesta pesquisa qualitativa apoiou-se na realização de entrevistas semiestruturadas com integrantes dos serviços de Ímola de ambas as nacionalidades. Assim, foram identificadas práticas relevantes que denotam uma participação efetiva de brasileiros e brasileiras, como educadores profissionais e assistentes de base, que não apenas impactaram o cotidiano assistencial como também colaboraram para a construção de cultura e relações inclusivas, inventivas, reflexivas e propositivas.
\end{abstract}

Palavras-chave: Reforma Psiquiátrica; Saúde Mental; inclusão social.

\begin{abstract}
This paper deals with the process of deinstitutionalization in the context of the psychiatric reform in Imola based on the narrative of Brazilians who participated in daily life there, throughout the nineties. The research that supports this paper sought to delineate the connections between Brazil and Italy regarding the actions that resulted in the closure of asylums and the establishment of territorial services, residences, associations, and cooperatives that supported social inclusion projects. The methodology used in this qualitative research was semi-structured interviews with members of the Imola care services of both nationalities. Relevant practices have been identified that indicate effective participation of Brazilians, as professional educators and basic assistants who have not only affected everyday care but also contributed to the cultural and inclusive, inventive, reflexive, and propositional relationships.
\end{abstract}

Key words: Psychiatric Reform; Mental Health; social inclusion. 


\section{Introdução}

Neste artigo, vamos tratar sobre a história da reforma psiquiátrica em Ímola, uma cidade de aproximadamente 64 mil habitantes, localizada no norte da Itália, região da Emilia Romagna. Daremos visibilidade para o processo de desinstitucionalização ali ocorrido, tomando um aspecto em especial: a prática dos brasileiros nos anos 90. Falaremos de conexões entre o Brasil e a Itália: contribuições, simpatias, identidades, parcerias, processos, dispositivos. Estas foram objeto de uma pesquisa específica, financiada pela Fundação de Amparo à Pesquisa do Estado de Minas Gerais (FAPEMIG), ao longo dos anos de 2011 e 2013: "A história da política de saúde mental: Minas Gerais e vínculos com Itália".

Não há novidade na presença de estrangeiros que querem conhecer, genericamente, serviços e práticas inovadores e de destaque internacional, como é o caso da Itália. Em estudo realizado em Trieste, sempre sobre o processo de reforma psiquiátrica, identificamos uma rica experiência de voluntariado que marcou a cidade desde o início do processo de desinstitucionalização no início dos anos 70. Mas o grande destaque, numérico, evidenciou uma presença brasileira - especialmente de profissionais originários da região sudeste - que sinalizou um impacto específico que é ainda atual (Goulart e outros, 2015). Este fluxo, que tomou a forma de uma expressiva participação na construção da política de saúde mental italiana, também se notabilizou em Ímola nos anos 90, com características singulares e relevantes.

Assim, abordaremos, neste artigo, um contexto preciso: os anos noventa do século $X X$, quando também se iniciava no Brasil a construção da reforma psiquiátrica e a estruturação da rede de atenção psicossocial. A Itália, nesta década, concluía o ciclo de fechamento de manicômios, sendo o de Ímola, um dos mais desafiadores dentre deles (Venturini, 2018, p. 39).

Muitos brasileiros participaram direta ou indiretamente da reforma psiquiátrica da cidade de Ímola, como operadores sociais, voluntários, pesquisadores, visitantes, estagiários e colaboradores externos (profissionais que traziam contribuições diversas, como artistas, palestrantes ou simplesmente participantes e apoiadores). Diferentemente de Trieste ou de outras cidades italianas, em Ímola ocorreu a constituição de um grupo bastante homogêneo, que operava de forma articulada e que se integrou profissionalmente às atividades e serviços de saúde mental. Procuraremos identificá-los, na sua condição de sujeitos ativos, delineando sua prática que remete à história de construção dos dispositivos que viabilizaram o processo de desinstitucionalização e possibilitaram a reinserção social dos ex internos dos manicômios, ampliando o escopo do trabalho de reabilitação social na rede de serviços territoriais que foi tecida na ocasião. 
A presença de brasileiros nos serviços de saúde mental de Ímola refletia a marca da cultura brasileira?

\section{Metodologia}

Os dados da pesquisa que serão aqui explorados, emergiram de depoimentos pessoais $^{1}$, entrevistas semiestruturadas ${ }^{2}$, realizadas face a face, individualmente e em grupo, entre 2012 e 2016, e também via correio eletrônico, visto que muitas destas pessoas eram de diversas partes do Brasil e algumas estavam ainda em território estrangeiro.

Perguntávamos, como "tópicos guia" (Gaskell, 2002, p. 66) porque estas pessoas tinham ido para a Itália e quais motivações os levaram a participar da reforma psiquiátrica de Ímola; como e através de quem entraram em contato com os serviços; qual foi a experiência vivida, o trabalho desenvolvido; o que deram e receberam desta experiência; o impacto da sua ação nos serviços de saúde mental e qual seria a avaliação desta prática. Alguns profissionais italianos, que trabalharam com brasileiros, foram também entrevistados. O objetivo era o de refletir, através de fontes orais, sobre o impacto da atuação dos brasileiros nos serviços em questão. Ao todo, foram realizadas 15 entrevistas, focadas em Ímola, sendo 9 delas com brasileiros e as demais, italianos.

Através das entrevistas com um grupo de informantes bastante homogêneo, analisadas tematicamente, emergiram espaços de trabalho e processos (dispositivos e procedimentos), que evidenciaram um estilo qualificado aqui como "brasileiro" (em Ímola nos anos 90), configurando um discurso coletivo bastante consistente.

O interesse investigativo e reflexivo abraçou a história de pessoas envolvidas no cotidiano de trabalho que construíram e sustentaram, para além e aquém do culto à ideia de grandes invenções e lideranças, concebendo os processos de mudança como microssociais, contraditórios, interativos, carregados de intenções e afetos. A inspiração da capacidade compreensiva originou-se a partir da Análise Institucional Francesa ${ }^{3}$ e da Psicologia Social Crítica brasileira ${ }^{4}$. O esforço historiográfico procurou dialogar com a micro-história, de perspectiva italiana 5 .

\footnotetext{
${ }^{1}$ Depoimentos de Ernesto Venturini e Adelaide Lucimar Fonseca Chaves, sistematizados em 2016.

2 Foram solicitados termos de consentimento, em conformidade com solicitação do Comitê de Ética da Universidade Federal de Minas Gerais, sendo que o número do processo CAE é 0570020300010. Para o uso dos nomes pessoais neste artigo, foi realizada consulta específica por e-mail.

${ }^{3}$ Aqui destacamos os nomes dos franceses René Lourau e René Barbier, e dos estudos de Heliana Conde de Barros Rodrigues.

${ }^{4}$ Destacamos a tradição de pensamento desenvolvida a partir da obra de Sílvia Lane e as concepções críticas do materialismo histórico.

${ }^{5}$ Salientamos aqui a perspectiva de trabalho de Carlo Ginzburg.
} 
Foi um percurso exploratório e de natureza qualitativa, que resulta em informações históricas e metodológicas relevantes e concernentes ao processo de desinstitucionalização ocorrido na Itália; ao lugar dos estrangeiros (brasileiras e brasileiros); e, ao delineamento do "tratamento em liberdade".

Iniciaremos compartilhando informações sobre Ímola e, a partir desta contextualização, indicaremos a participação brasileira e o seu processo (Venturini, 2018, p. 23).

\section{A cidade dos loucos: a grande transformação}

O primeiro internamento manicomial de pessoas com transtornos mentais na região da Emilia Romagna ocorreu na época da República Cisalpina (1797-1802) criada por Napoleão Bonaparte, quando havia apenas uma pequena enfermaria de quinze camas, dentro do hospital Santa Maria della Scaletta. Posteriormente, o bispo da cidade - Giovanni Maria Mastai Ferretti, futuro Papa Pio IX, que fora o responsável religioso e político pela cidade de Ímola - decidiu expandir a estrutura. Assim, em 1844 , foi inaugurada a nova enfermaria no mesmo hospital geral, com capacidade de 80 lugares, recebendo também pacientes de outras cidades vizinhas, tais como Forlí, Ravenna e Ferrara. Esta ala foi chamada de "Asilo" (Giacanelli, Iachini \& Migani, 1994).

Desde então o manicômio de Ímola foi ampliado sucessivas vezes. Em 1869, nova obra foi feita pelo arquiteto Antônio Cipolla a pedido do diretor administrativo do hospital naquela época, Luigi Lolli, que se baseou no modelo de gestão dos manicômios franceses, inaugurando-o em 1880 e denominando de Il Manicomio Centrale, com capacidade para 800 leitos em uma área de extensão de 40.000 metros quadrados. Porém, logo se tornou pequeno pela quantidade de pacientes que passou a receber das mais diferentes cidades italianas: Modena, Arezzo, Bari e Milão. Devido a esta intensa demanda, em 1890 foi construído um anexo ao manicômio, denominado de Il Manicomio dell'Osservanza, com uma área de 75.000 metros quadrados e capacidade para abrigar 1000 pacientes (Migani, 1994). Após a morte de Luigi Lolli, em 1896, os dois manicômios se tornaram insustentáveis, em virtude de sua má administração. As condições de hospedaria dos pacientes e o ambiente se tornaram degradados, fazendo com que o Il Manicomio Centrale fosse vendido para a província de Bologna em 1897, e denominado inicialmente com Manicomio provinciale di Bologna in Imola, para depois ser chamado de Ospedale psichiatrico provinciale Luigi Lolli. Com esta cisão, as duas estruturas (Lolli e Osservanza) ficaram autônomas, recebendo pacientes de diferentes localidades, sendo que o Osservanza receberia os pacientes crônicos (Galassi, 1989). 
Assim, os hospitais psiquiátricos Luigi Lolli e Osservanza, ao longo de dois séculos, foram referência e fonte de trabalho para a pequena cidade e para as pessoas que ali trabalhavam como enfermeiras/os, nas lavanderias, nas cozinhas, ou ainda como alfaiates e costureiras. Outros, forneciam materiais e outros préstimos para o funcionamento da máquina manicomial. Na década de 50 do século passado, a população dos dois nosocômios oscilava entre 2.500 e 3.000 indivíduos. A fama de cidade dos loucos era análoga com a de Barbacena, em Minas Gerais e, na região da Emilia Romagna, dizer que "ir para Ímola" significava "ser louco", ou "ir para o manicômio" (Venturini, 1995).

A desinstitucionalização e a reforma psiquiátrica, como na maior parte da Itália, no que diz a respeito a superação e fechamento dos Hospitais Psiquiátricos, teria seu início apenas no ano de 1978, com a Lei 180, que, efetivamente, proibiu a construção de novos hospitais psiquiátricos na Itália; proibiu novas internações, regulamentou o tratamento sanitário obrigatório de modo a impedir o sequestro dos doentes mentais sem enquadramento jurídico protetivo, resgatando a necessidade de consentimento e o caráter voluntário do processo, além de garantir o direito a comunicação e a informação do usuário (e seus familiares) e reorientar a assistência para os serviços extra-hospitalares comunitários e territoriais (Goulart, 2004, 2006).

Como resultado da lei, foi criado, em Ímola, um Serviço de Diagnóstico e Tratamento para a admissão de pacientes agudos e um único Centro de Saúde Mental com características territoriais, que agregaria posteriormente um Hospital de Dia e um Centro Diurno. Mas, os dois hospitais psiquiátricos ainda resistiram com sua população encarcerada, embora não recebessem mais pacientes, até 1987, quando efetivamente começou o processo de fechamento. Para tanto, foi indicado por uma associação de familiares de usuários - "Al Margine" - o nome do psiquiatra Ernesto Venturini, que trabalhara com Franco Basaglia, em Gorizia e em Trieste, assumindo assim a direção dos antigos hospitais de Ímola - Lolli e Osservanza - para aplicar plenamente a Lei 180, na condição de diretor do Departamento de Saúde Mental. Já a partir de 1988, teve início o projeto de desinstitucionalização, o "Projeto Valerio" (Venturini, 2018, p. 26), que envolveu usuários, familiares e outros cidadãos, através de associações de voluntariado e da criação de cooperativas sociais. A primeira cooperativa foi a "Tragitti", em 1983, constituída pela Associação de familiares "Al Margine", abrindo espaço para o "Privato Sociale" (setor privado social) que teve um papel fundamental na reforma psiquiátrica imolense. As cooperativas sociais, não tinham objetivos lucrativos, prestavam serviços sociais e assistenciais, sendo financiadas e controladas pelo setor público. Elas, foram criadas também para possibilitar a contratação das novas e diversificadas figuras profissionais, geralmente 
jovens e comprometidos com a reforma psiquiátrica, que integrariam as equipes dos novos serviços.

O desafio da transformação foi concluído no dia 31 de dezembro de 1996, quando os manicômios foram totalmente fechados e substituídos por uma rede de serviços abertos e territoriais (Venturini, 2018, p. 117). Foi este o processo que atraiu a participação de brasileiros, que procuraremos focalizar a seguir, desenhando um percurso específico que revela alguns aspectos do processo de desinstitucionalização em curso ao longo dos anos 90. Antes de mais nada, falaremos das pessoas entrevistadas e suas expectativas, suas primeiras inserções e locais, para, em seguida, descrever as práticas que realizaram.

\section{Atravessando o Atlântico: razões e paixões}

Variadas foram as motivações que levaram brasileiras e brasileiros a participarem da reforma psiquiátrica de Ímola. Os diversos visitantes que iam conhecer os serviços estavam interessados no processo de reforma psiquiátrica que era atuado na Itália, mas foram também influenciados pela estreita ligação que o diretor dos serviços de saúde mental de Ímola tinha com o Brasil e com a América Latina. Venturini, experiente integrante da Psiquiatria Democrática e estreito colaborador de Franco Basaglia, foi responsável, no Brasil, por um convênio de colaboração patrocinado pela Organização Mundial da Saúde e Organização PanAmericana da Saúde entre a Região da Emilia Romagna (região onde se encontra a cidade de Ímola) e América Latina. Deste modo, estiveram nos serviços de Ímola, como observadores institucionais, diversos nomes da reforma psiquiátrica brasileira como: Domingos Sávio e Regina do Nascimento do Ministério da Saúde, Paulo Amarante da Fundação Fiocruz, Adail Medeiros da Secretaria de Saúde de Pernambuco (ficou um período com médico visitante), Virgílio de Matos, professor de direito da Universidade Federal de Minas Gerais, Francisco Caminha, psiquiatra do Rio de Janeiro, Fernanda Nicácio, professora da Universidade de São Paulo, Willians Valentini e Ana Maria Knippel do Hospital Cândido Ferreira de Campinas, Geraldo Peixoto da Associação de familiares, dentre outros.

Como parte deste convênio patrocinado pela OMS/OPAS, foram organizados em Ímola e Bologna, dois cursos para dirigentes de serviços de saúde mental da América Latina, dentre os quais o Brasil. Foi apresentado aos participantes todo o Programa de saúde em geral e dos Serviços de saúde mental da Região Emilia Romagna, além da realização de visitas técnicas às cooperativas sociais. Nestes cursos, os participantes, relatavam a situação da saúde, em particular a saúde mental, nos seus respectivos países. Esta apresentação resultou em ricos debates. 
No primeiro curso, em maio de 1999, (De Platô e Venturini, 2000), participaram do Brasil Ana Pitta e Alfredo Schechtman da Comissão Nacional de saúde mental (Brasília) e Gina Ferreira, psicóloga do Rio de Janeiro, que seria, posteriormente, uma das construtoras do projeto "De volta para casa" $(1996)^{6}$.

No segundo curso de formação, destacaram-se Pedro Gabriel Delgado da Comissão Nacional de saúde mental (Brasília), Erotildes Delgado, representante da luta antimanicomial do Rio de Janeiro e Paulo Amarante da Fundação Fiocruz, atuando como professor do curso e já sinalizando os resultados práticos do intercâmbio de experiências. Amarante foi um dos três profissionais estagiaram nos serviços de Ímola através desta convenção da OMS/OPAS. Além dele, participaram Gustavo Couto, psiquiatra de Recife; Jeane Lacerda, psicóloga de Recife, ambos vinculados à gestão pública em saúde.

Vários pesquisadores brasileiros desenvolveram trabalhos junto ao Departamento de Saúde Mental, como: Luiz Antônio Baptista, pesquisador e professor de psicologia social da Universidade de Niterói, Virgílio de Matos, professor de direito da Universidade Federal de Minas Gerais e Maria Stella Brandão Goulart, então pesquisadora e professora de Psicologia social da Pontifícia Universidade Católica de Minas Gerais.

Os serviços de Ímola receberam, por outras vias, também outros visitantes e voluntários/as. Destacamos que o número de voluntários brasileiros em Ímola foi menor em relação a Trieste, ainda que sua participação tenha sido particularmente intensa. Nos anos 90, o fluxo de brasileiros que queriam aprender com a experiência italiana já repercutia o processo de reforma que se iniciava no Brasil com experiências de mudanças que vinham se multiplicando no Brasil. Eram experiências, que, como no caso de Santos, São Paulo, Recife e Belo Horizonte, tornaram-se os novos pontos de referência da reforma brasileira (Lancetti \& Amarante, 2013, Goulart, 2006). Muitos vieram atraídos pela efervescência da vivência em Trieste, e outros vieram diretamente a Ímola.

Diferentemente de Trieste, a possibilidade de um vínculo profissional, através das cooperativas sociais, determinou a constituição de um grupo bastante coeso. Eram, em sua maioria, terapeutas ocupacionais, psicólogas, mas também pessoas que não tinham formação específica (químico, estatístico, protética) e se qualificaram, como operadores sociais (educadores e assistentes de base) na prática e ao longo do processo de inserção nos serviços, como: Ana Sílvia Fuschino, Lucia Saponi, Edison Maranzato, Ademir Corazza, Maria Eduarda de Almeida Amos, João Carlos Araújo,

\footnotetext{
${ }^{6} \mathrm{O}$ projeto "De volta para Casa" desenvolvido para Gina Ferreira nas prefeituras de Angra dos Reis e Parati, recebeu um prêmio da Associação Mundial de Reabilitação Psicossocial em 1996, no seu V Congresso, sendo, a partir de 2003) adotado em todo o Brasil pelo Ministério da Saúde.
} 
Adelaide Lucimar Fonseca Chaves, Adriana Luciene Fonseca Chaves e Adriana Aikawa da Silveira Andrade, entre outros que relataram suas histórias.

As primeiras brasileiras, que chegaram em Ímola em 1989, foram Ana e Lucia. Elas, formadas em Terapia Ocupacional na Universidade de São Carlos (São Paulo), já conheciam os revolucionários serviços de Trieste e souberam também sobre o processo de reforma psiquiátrica de Ímola pela professora Denise Barros da Universidade de São Paulo (USP). Atraia, segundo elas, a ideia de que se pudesse trabalhar com a saúde mental sem o manicômio, em um espaço humanizado. Elas aderiram à proposta, indo trabalhar e habitar na primeira residência comunitária "Cá del Vento", organizada para pessoas que haviam vivido mais de 30 anos no manicômio. Através de contato com estas duas primeiras terapeutas ocupacionais, outros brasileiros e brasileiras foram atraídos: Edison, Ademir, Maria Eduarda e João; principalmente eles eram amigos da Universidade de São Carlos (São Paulo).

Edison, estatístico, foi para Itália, em 1991, e integrou-se ao nascente "Centro Diurno Il Girasole", em 1994, como responsável artístico devido a suas habilidades pessoais. Já Ademir, químico de formação, também chegou em 1991 e logo se envolveu com o efervescente projeto de desinstitucionalização do hospital psiquiátrico de Ímola. Ele obteve sua cidadania italiana, na condição de descendente, em 1994, e se integrou na residência Cá del Vento.

Lucimar começou sua experiência italiana por Trieste (1989). Ela, com formação em Psicologia pela Fundação Mineira de Educação e Cultura (FUMEC) de Belo Horizonte (Minas Gerais), vinha de uma prática ativista no Brasil desde 1987, participando da luta antimanicomial, chegando em Ímola, no ano de 1992, cativada pelo "calor da revolução". Foi logo contratada pela Associação de familiares " $A$ I Margine" e depois pela cooperativa social "Tragitti" para trabalhar, inicialmente, na nova residência para os ex internos: "La Pascola". Em 1993, Lucimar estimulou a vinda de sua irmã, Luciene, que tinha formação em prótese dentária pela Universidade Católica de Minas Gerais. A ideia inicial era a de dar atenção odontológica aos pacientes ainda internos. Acabou se vinculando inicialmente no Centro Diurno "Il Girasole" e logo depois foi também contratada pela cooperativa "Tragitti", para trabalhar em uma residência chamada "Macondo". Neste espaço, foi trabalhar também uma outra brasileira, a Adriana, psicóloga, que fora para a Itália, em 1996, acompanhando seu marido, que fazia doutorado na Universidade de Bologna. Adriana contatou Lucimar para conhecer os serviços de saúde mental de Ímola e daí foi trabalhar primeiramente como educadora para, em seguida, atuar como coordenadora desta mesma residência. Seu marido, também psicólogo, Ju de Andrade, realizou alguns projetos no hospital psiquiátrico: um curso de expressão corporal e alguns espetáculos de dança. 
A reforma psiquiátrica de Ímola contou ainda com a colaboração de outros brasileiros e brasileiras, que não faziam parte dos serviços, mas apoiavam o processo de reforma e os amigos envolvidos. Foi o caso de Flávia Hofmann Mota, que vivia em Bologna e por várias vezes participou organizando espetáculos e eventos dentro dos ex manicômios, em processo de desinstitucionalização. Houve ainda a colaboração de vários músicos brasileiros, como Nélson Machado, Rogério Tavares, José Eduardo e outros que animaram as festas públicas que deixavam as marcas da cultura brasileira (músicas, danças, cores, adornos etc). Os carnavais brasileiros no ex manicômio se tornaram famosos, na época, e atraíram crescentemente os habitantes de Ímola, Bologna e outras cidades vizinhas (como também ocorreu em Trieste). Eram eventos culturais e artísticos que construíram pontes e uniam a cidade e o território manicomial em processo de desconstrução, com intensa participação dos pacientes e dos imolenses. Procurava-se, através das intervenções culturais planejadas pelas equipes das cooperativas que inseriam os brasileiros, a transcendência dos muros concretos e subjetivos do manicômio: o medo, o preconceito e a indiferença. Os brasileiros e brasileiras, estrangeiros/as, ocupavam um lugar bastante específico e sintônico com a alteridade da loucura, evidenciando a diversidade e as especificidades da exclusão social: imigrantes e "doentes mentais". Eles produziam encontros inéditos onde uma certa liberdade de trânsito emergia. Novas relações e presenças embaralhavam os códigos do "viver juntos" na cidade que reinventava e superava o seu espaço e cultura manicomiais.

Os lugares sociais foram reformatados pela participação daqueles que forma perfilando novas identidades profissionais, como assistentes de base, operadores sócio-sanitários ${ }^{7}$ e educadores sociais, que desenvolviam projetos de reinserção social junto às associações e às cooperativas (nos centros diurnos, residências, em eventos) ou em atividades de apoio ao Departamento de Saúde Mental de Ímola. A prática no contexto destas iniciativas foi descrita nas entrevistas e delineia a relevância da inserção do conjunto de pessoas identificadas nas seguintes estruturas: residências Cá del Vento, La Pascola, Casa Basaglia, Macondo, Grupo Apartamento Pambera -, Centro Diurno Il Girasole e Associação Pas e Temp. Estes espaços serão abordados a seguir, pois são, justamente, os espaços de inovação institucional do processo de desinstitucionalização em Ímola (Venturini, Degano, Gramantieri, 1995).

\section{Espaços de inserção e invenção}

\footnotetext{
${ }^{7}$ A profissão de operatore sócio sanitário foi homologada no dia 21 de fevereiro de 2001, com o objetivo de integrar o trabalho realizado do assistente de base, que atuava especificamente no campo da saúde com a figura profissional do assistente domiciliar e dos serviços tutelares que atuava especificamente na área social, integrando as funções, responsabilidades e competências das duas áreas em um contexto único (http://www.operatoresociosanitario.net/chi-e-l-oss).
} 
No processo de fechamento dos hospitais psiquiátricos, foram criadas, segundo o seu gestor Ernesto Venturini, ao longo de pouco mais de uma década, uma cooperativa de inserção no trabalho ${ }^{8}$ e quatorze associações ${ }^{9}$ de usuários, familiares, operadores sociais e cidadãos imolenses. Estes lugares expressavam a vontade de criar espaços transversais de cidadania, onde se concretizava o reconhecimento recíproco dos direitos e das necessidades de todos - tanto as pessoas assim chamadas "doentes" quanto as "saudáveis". Para abrigar ex internos, que, devido ao longo período de internamento, não puderam retornar às suas casas originais, foram realizadas também vinte e quatro residências e grupos de apartamentos (Venturini, 2018 , p. 4). A coordenação das residências era concedida, através de licitações, às oito cooperativas sociais ${ }^{10}$ que foram surgindo neste processo e as que foram atraídas.

Neste artigo, falaremos apenas das residências ${ }^{11}$ e associações ${ }^{12}$ onde foram identificadas a presença de brasileiros e, posteriormente, sobre as práticas que eles realizaram.

Quando as primeiras terapeutas ocupacionais brasileiras chegaram a Ímola, já existia, como dissemos, uma Associação composta por familiares e cidadãos imolenses, Al Margine, que, por sua vez, apoiou a criação de outras duas associações. Uma era de operadores sociais, a Girasole, e a outra, a Ca' del Vento, composta por ex internos e cidadãos de Ímola. Esta associação constituiu a primeira residência com características autogestionárias. O associacionismo progressivamente se expressou em diferentes campos - teatro, educação, poesia, comunicação, esporte, arte, defesa dos direitos das mulheres, dos direitos dos pacientes. Nós nos limitaremos falando apenas sobre Pas e Temp e Van Gogh (uma associação desenvolvida com grande participação de brasileiros). As residências foram se estruturando, na medida em que as pessoas eram preparadas para deixar o espaço manicomial. Estas estruturas foram espaço de invenção para todos, inclusive brasileiras e brasileiros.

\section{A Associação "Il Girasole" e seu Centro Diurno}

Esta associação nasce no calor das primeiras intervenções dentro do manicômio e já em 1989, e organizou o segundo Centro Diurno de Ímola, com o mesmo nome: II

\footnotetext{
${ }^{8}$ Cooperativa Itaca.

${ }^{9}$ Al Margine, Tribunale dei Diritti del Malato, Teatro Mazzolanza-Sagrè, Il Girasole, Ca' del Vento, Scuola di Alfabetizzazione, Pas e temp, Comitato per l'Impresa Sociale, Cicoria, Gruppo di poesia, Van Gogh, Polisportiva Eppur si muove, Teatro Gruppo Tabù, Oltre la Siepe e uma outra organizada em torno do tema da imigração: Trama di terre.

${ }^{10}$ Tragitti, Al Margine Onlus, Sol.co, Sea.Coop, La Linea d'Ombra, Fuoric'entro, Consorzio Ippogrifo, Atlas.

${ }^{11} \mathrm{Ca}^{\prime}$ del Vento, Pascola, Casa Basaglia, Macondo, e Gruppo Appartamento Pambera.

12 Al Margine, Il Girasole, Cà del Vento, Pas e Temp, Van Gogh.
} 
Girasole (O Girassol). Este foi gerenciado, no início, pela associação "Al Margine" e, alguns anos depois, pela cooperativa "Tragitti". Ambas viabilizaram as contratações de equipe. O Centro Diurno, nascido dentro de um dos pavilhões do hospital psiquiátrico em processo de fechamento, funcionava, inicialmente, durante três dias na semana, como "um caldeirão de ideias", em uma grande sala do andar térreo. Seu objetivo era propor atividades reabilitativas ou inclusivas aos internos dos manicômios, confrontando a sua cronificação.

Assim, foram identificadas as primeiras pessoas interessadas em ir morar nos espaços residenciais. Nutrido, segundo a psicóloga brasileira, Lucimar, pelos "desejos e necessidades" dos usuários, o Centro Diurno Girasole foi se ampliando e diversificando as suas funções, conquistando espaço físico e versatilidade, onde se destacavam as atividades artísticas.

Com o fechamento do manicômio, em 1996, este Centro Diurno saiu da área do hospital para uma casa, "de portas abertas", de dois andares nos arredores do parque. Sua clientela mudou e começaram chegar pacientes mais jovens e menos cronificados, vindos do Centro de Saúde Mental da Villa dei Fiori e da enfermaria do Serviço de Diagnóstico e Atendimento. Aos poucos, teve início um trabalho de equipe, que discutia os casos e promovia integração de ações. Com este Centro Diurno, colaboraram Lúcia, Ana, Maria Eduarda, Lucimar, Edson e Luciene, sendo esta última, como voluntária.

Este Centro Diurno realizou um esforço de integração dos ex internos na cidade, se reapropriando dos espaços públicos e contribuindo para criar nos lugares dos manicômios desconstruídos espaços, de vida e de cidadania. Ao mesmo tempo, no "Il Girasole", se afirmava o direito ao supérfluo, a atitude produtiva e a negação do produtivismo, estimulando curiosidades e inovações. Assim nasceu a Associação van Gogh, que dava visibilidade aos produtos artesanais e artísticos, viabilizando sua comercialização: uma iniciativa associativista bem brasileira.

\section{Associação van Gogh}

Esta associação contou com a colaboração de artistas reconhecidos, como Gió Urbinati (ceramista), de alguns músicos, inclusive brasileiros, e artistas plásticos de outros países. Seus integrantes realizaram, até mesmo, uma mostra de quadros e instalações artísticas utilizando um pavilhão do ex manicômio que já estava em desuso, contando com a participação de artistas de várias cidades italianas e outros países. Trabalhavam sempre na busca de parcerias, pois assim o trabalho terapêutico era enriquecido de um valor social de integração. 
Organizavam-se cursos de arte em colaboração com outras associações, onde podiam se inscrever usuários dos Centros Diurnos e pessoas da cidade de modo geral. Havia estreita colaboração com uma paróquia da cidade na organização de uma mostra de presépios, no período do Natal, e ali se envolvia em um trabalho comum os jovens da paróquia e usuários do "Il Girasole" na produção das peças de arte e na organização do evento. E assim tantos outros eventos aconteciam em colaborações com artistas plásticos e músicos, italianos, brasileiros e colaboradores de outros países europeus. E aqui são citados vários exemplos, como o intercâmbio organizado junto a outros Centros Sociais da cidade com um grupo de países como a Finlândia, Alemanha, Holanda, Dinamarca, Suécia e outros, a recepção no Centro diurno de estudantes da cidade de Novi Sad da ex-Jugoslávia atingida pela guerra, a recepção com outras associações e prefeitura da cidade, de crianças atingidas pelo desastre na usina nuclear de Chernobyl, que viam todos os anos elaborar os efeitos danosos daquele desastre sobre a sua saúde, segundo informações do Diretor de Saúde Mental de Ímola (Ernesto Venturini).

\section{A associação e a residência "Cá del Vento"}

No ano de 1990, das diversas assembleias populares realizadas dentro do manicômio e do trabalho do Il Girasole, surgiu a Associação "Cá del Vento13", Casa do Vento, formada por cidadãos e ex internos, que constituiu subsequentemente a primeira residência autônoma de ex internos. Ela foi criada dentro do parque do manicômio Osservanza e seus moradores puderam gerir diretamente todos os aspectos da vida dentro da residência com total autonomia. Eles recebiam financiamento da "Azienda Sanitária da Saúde" e decidiam de forma independente, através um processo de licitação pública, quem e como deveria ocorrer o cuidado e apoio ao seu cotidiano 0 fato dos moradores, ex internos, fazerem parte de uma associação que gerenciava as suas próprias vidas, promovia a consciência de cidadania e criava condições para a participação comunitária.

Nos meses iniciais da residência foi montada uma equipe formada por algumas enfermeiras e jovens sem experiência manicomial, incluindo as duas brasileiras, Lucia e Ana, que, diferentemente dos outros concordaram em viver dentro da residência. Mais tarde, pareceu mais apropriado montar um grupo de trabalho apenas com pessoas sem vínculos institucionais diretos. As enfermeiras saíram da residência para se envolverem em outros projetos de desinstitucionalização Depois de um certo tempo chegaram João, Ademir, Edson e Maria Eduarda. Segundo os relatos, através

13 http://www.news-forumsalutementale.it/imola-i-20-anni-di-ca-del-vento/ Artigo sobre os 10 anos da associação, celebrado em 2010. 
da interculturalidade (as histórias das brasileiras sobre o seu país, as suas famílias), se criou na "Cá del Vento" e posteriormente na residência "Pascola", uma situação de familiaridade muito forte. Após quatro anos de funcionamento, já faziam parte de uma rede europeia de recovery, destinada à integração de pessoas portadoras de deficiências, com sede em Amsterdam na Holanda e que se encontrava regularmente, configurando um movimento internacional de usuários e ex usuários que reivindicam seu "recuperado" protagonismo nas escolhas relativas à sua saúde mental (Gramantieri, 1995).

\section{A Associação "Pas e Temp"}

No ano de 1992, foi fundada a Associação Pas e Temp "passa o tempo"14, que era composta por usuários do serviço de saúde mental, familiares, profissionais, e pessoas da cidade. Entre as várias atividades, esta associação produzia um jornal homônimo que era distribuído nas bancas de jornal da cidade, com o apoio do principal jornal da cidade, chamado Sabato Sera, que muitas vezes servia de caixa de ressonância das tantas atividades realizadas pela rede de serviços alternativos desinstitucionalizantes. A associação fazia parte de um comitê chamado Comitato per l'impresa sociale (Comitê para Empresa Social), composto por várias associações e que tinha como objetivo organizar eventos e iniciativas para a criação de uma rede de serviços alternativos ao antigo manicômio. Uma das principais iniciativas deste comitê era organizar, todos os anos, uma grande festa dentro do parque do manicômio, durante vários dias, convidando a cidade a participar. Para tanto se apostava na qualidade do evento, convidando artistas e músicos famosos a se apresentarem, bem como ótimas peças de teatro. Esta grande festa era chamada de "Parco in Festa" (Parque em Festa).

A Associação trabalhava em parceria com uma escola de primeiro grau, e tinha uma classe dentro do Hospital Psiquiátrico, com o objetivo de alfabetizar os usuários que desejassem aprender a ler e escrever. Os pacientes, eram alunos, todos iguais, a partir de um ponto de vista legal, àqueles da escola pública, localizada próximo ao hospital. A escola colaborava ativamente com as atividades resultantes da reforma em saúde mental. Exemplo disto, era a participação das crianças nas festas realizadas no parque e no grupo de teatro criado pela "Pas e Temp", quando se relacionavam com os usuários do manicômio, sem medo e sem preconceitos (Degano, 1995).

Lucimar, a psicóloga, comenta sobre o trabalho de pesquisa que realizou pelo "Pas e Temp", fazendo entrevistas nos vários espaços da sociedade, frequentados por

\footnotetext{
14 Note-se que não se limita a ideia de "passatempo" como um divertimento e sim a uma dimensão existencial relativa à vida que segue seu rumo inclemente.
} 
pessoas que viveram ou ainda viviam no manicômio. Esta pesquisa visava entender o nível de aceitação dos chamados "loucos" na sociedade e a integração deles. O resultado foi que, segundo ela, "na maioria dos proprietários de bares e dos comerciantes, havia uma relação de afeto, e até de certa proteção, com os pacientes ou ex-pacientes do manicômio".

\section{A residência "La Pascola"}

Esta foi a segunda residência imolense: "La Pascola", que era o nome de uma antiga escola elementar. Nela, trabalharam Lucimar e Ana. A residência foi instalada em uma colina mais distante do centro, em um único prédio disponível - uma antiga escola - que foi renovada; o que dificultava o processo de reinserção dos residentes na vida da cidade. A seleção dos usuários interessados em sair do manicômio e ir morar nesta residência ocorreu a partir das reuniões no Centro Diurno "Il Girasole". Houve um processo de adaptação fora do manicômio: os usuários, começaram a passar dias na casa onde eles morariam e a noite retornavam aos pavilhões do manicômio para dormir. As assembleias passaram a ser feitas na nova residência, para decidir o funcionamento da casa, o menu, as compras e responsabilidades do dia a dia. Para ela, havia uma equipe técnica do Departamento de Saúde Mental - um médico psiquiatra e uma assistente social -, que não estavam presentes na casa todos os dias, mas sim de acordo com as necessidades. A psicóloga Lucimar descreve que havia um motorista, alguns enfermeiros, vinculados ao serviço de saúde pública e que já tinham trabalhado no manicômio, além de assistentes de base, que atuavam no campo da saúde, e uma nova figura profissional, os educadores profissionais, que trabalhavam no campo do social e eram contratados pela associação de familiares " $A l$ Margine".

Havia uma supervisão com equipe do Departamento de Saúde Mental, além de reuniões sistemáticas que serviam para discutir os projetos individuais a serem apresentados e acordados com os usuários, em relação as suas próprias vidas, projetos coletivos, o funcionamento da casa e ainda para resolver os conflitos que nasciam das diferentes formas de trabalhar. Ocorriam também assembleias semanais "muito ricas e proveitosas: se discutia de tudo", segundo a psicóloga Lucimar. Além disso, eram oferecidos aos operadores alguns cursos periódicos de formação para os profissionais do serviço de Saúde Mental.

\section{A residência "Casa Basaglia"}


A "Casa Basaglia" foi a terceira residência criada no processo de desinstitucionalização. Foi constituída fora do espaço do manicômio, em um bairro popular da cidade de Ímola, com critérios específicos de uma arquitetura de boa qualidade para uma residência e respeitando, também, os padrões ecológicos.

Contra a sua abertura, os vizinhos enviaram ao prefeito da cidade um documento de protesto, expressando seus medos. Nasceu um forte debate público em relação ao direito de viver na cidade, por ex internados em hospital psiquiátrico. Entre as muitas intervenções, foi importante a posição do bispo: ele falou em favor da inclusão de usuários naquela residência, durante a homilia da missa dominical.

Afinal a residência foi inaugurada com a presença da Senadora Franca Basaglia em "uma cerimônia memorável". A cooperativa "Tragitti" ganhou a licitação, oferecendo uma equipe profissional constituída por assistentes de base e educadores profissionais. Nesta residência trabalharam, inclusive juntos, por certo tempo, Lucimar (psicóloga), Ademir e Edison, todos eles inseridos como como educadores profissionais. Foi inclusive realizado um vídeo amador, por Ademir, compartilhando esta experiência: "Ensaios".

\section{A residência "Macondo"}

Esta residência foi localizada fora das fronteiras do distrito de Ímola; em Ravenna, respondendo a demandas específicas de envolvimento de diferentes áreas da Romagna. Tratava-se de implementar uma transferência de competências e gestão de serviços de saúde mental de Ímola para outras Unidades Locais de Saúde. Concretamente, haviam ex-internos que eram originários desta região e que deveriam ser reabsorvidos como cidadãos em um processo de reinserção que dizia respeito a uma outra estrutura administrativa. As resistências e os conflitos entre diferentes prestadores de serviços, com visões científicas e ideológicas nem sempre articuláveis, determinaram situações difíceis, em detrimento dos pacientes e das equipes. $\mathrm{Na}$ verdade, a avaliação final desta operação foi positiva.

Na residência chamada "Macondo", com a cooperativa "Tragitti", trabalharam Adriana, psicóloga, por um longo período, tornando-se a coordenadora da equipe em função da sua formação em psicologia hospitalar, e Luciene, que trabalhou como assistente de base por certo tempo neste espaço. Esta residência abrigava expacientes com desabilidades grave, com pouca capacidade comunicativa e de integração.

\section{O Grupo Apartamento "Pambera"}


Os grupos de apartamentos, ao contrário das residências, proporcionavam um menor número de moradores e com maior autonomia. Os apartamentos estavam localizados no centro da cidade.

Estes grupos apartamento foram construídos com a mesma lógica que orientou a definição das demais residências: o caso a caso discutido e negociado. "Pambera" foi resultante do último esforço de esvaziamento dos pavilhões dos manicômios, mobilizando resistências e inseguranças intensas, assim como confrontando lógicas de trabalho bastantes dispares entre os antigos enfermeiros e as novas equipes de desinstitucionalização que foram imprimindo uma lógica de abertura e que apontava para uma radical e definitiva transformação que seria celebrada na cidade de forma ritualizada e poética através de uma grande festa (Venturini, 2016, p. 39).

Luciene trabalhou exatamente neste processo, inserida inicialmente no pavilhão, preparando os pacientes para a saída, enfrentando a resistência dos enfermeiros e, posteriormente, vivendo o desafio do novo espaço residência que tomou a forma de um dos dois primeiros grupos apartamento, que ficava situado na via Pambera (rua Pambera).

\section{A prática e seu sentido}

Viver o desafio, estrangeiro, da loucura, foi uma escolha para muitos. A inspiração da reforma psiquiátrica italiana ultrapassou fronteiras e abriu novas possibilidades de trânsito.

A inserção dos brasileiros e das brasileiras nas atividades de reinserção no Centro Diurno "Il Girasole" e nas Residências nos informa sobre a prática que se delineou e seus desafios. Destaca-se também o envolvimento com o processo de desinstitucionalização dentro dos pavilhões, implicando no contato direto com os internos e com as equipes, tensionados entre a resistência ao processo e o desejo de mudança, ainda que, as resistências, especialmente dos enfermeiros, não possa ser generalizada, pois, em geral, sinalizou-se um clima de grande colaboração entre brasileiros e o staff italiano. Não pode ser ignorada a participação ativa de muitos enfermeiros do antigo asilo no processo de desinstitucionalização. Sabe-se, de fato, que o comportamento do pessoal que trabalha em um hospital psiquiátrico é expresso em uma lógica abrangente e excludente, muitas vezes incorporada apenas inconscientemente. A equipe de enfermagem é ela mesmo uma vítima de violência institucional, que se refere a outras responsabilidades mais pesadas - os médicos, administradores, políticos, a mesma comunidade "externa". Mas, sem dúvida, se essa equipe não manifestar uma vontade determinada de contrastar o absurdo da 
instituição, acaba sendo esmagada pela lógica burocrática, pela sua inércia totalizadora.

A inserção profissional dos brasileiros e brasileiras se deu através de modalidades que, no entanto, foram fundamentais para os processos de reforma italianos: a figura do educador profissional e o assistente de base, e posteriormente os operadores sócio-sanitários. Estes, realizavam as funções de atenção e cuidado à saúde assim como as atividades de inclusão, marcados por corajosa inventividade. As funções destas duas figuras profissionais eram distintas, mas não rígidas. Mais tarde, as duas funções foram unificadas, através de um ato deliberativo, nacional, em uma

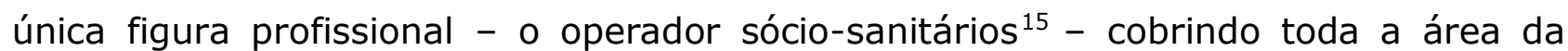
saúde e não apenas a saúde mental. Para os assistentes de base eram atribuídas funções mais tipicamente vinculadas ao campo da saúde e no controle do cuidado e das condições hoteleiras. Eram profissionais responsáveis pela limpeza e organização da casa, da cozinha, preparavam refeições, cuidavam do vestuário, "sempre tentando envolver os usuários nos vários trabalhos domésticos". Se por exemplo um assistente de base tinha "afinidade" com um usuário e "surgia a vontade de participar de uma atividade lúdica, cultural ou esportiva, era aquele assistente quem acompanhava e o educador ficava em casa". Havia muita flexibilidade.

Os educadores tinham a função de acompanhar mais de perto os usuários nas diversas atividades de suas vidas sendo responsáveis por organizar conjuntamente as atividades cotidianas (em assembleias e também individualmente), "seguindo projetos que eram delineados nas reuniões da equipe e concordado com cada um dos residentes". Os processos educativos se traduziam em uma atitude de acompanhamento dos usuários, com atenção para o resgate da dignidade, do direito de ser e viver.

Os educadores "tinham o papel de fazer com os residentes um percurso para readquirir todo o aprendizado que o manicômio Ihes havia roubado, ou nunca os dera o direito de aprender".

Estes perfis permitiram realinhamentos nas relações profissionais com os enfermeiros e psiquiatras que protagonizavam no campo da saúde mental, especialmente nos redutos manicomiais. Os novos perfis profissionais, ainda que introduzissem vínculos trabalhistas frágeis, falavam literalmente outra linguagem e viabilizavam a interdisciplinaridade com grande radicalidade, além de apontar para uma perspectiva não tecnicista, onde os atributos e habilidades pessoais passaram a

\footnotetext{
15 A profissão de operatore sócio sanitário foi homologada no dia 21 de fevereiro de 2001, com o objetivo de integrar o trabalho realizado do assistente de base, que atuava especificamente no campo da saúde com a figura profissional do assistente domiciliar e dos serviços tutelares que atuava especificamente na área social, integrando as funções, responsabilidades e competências das duas áreas em um contexto único. http://www.operatoresociosanitario.net/chi-e-I-oss.
} 
fazer diferença. $O$ questionamento ativo dos especialismos constituíam processos que eram intensos do ponto de vista emocional, enquadrando a luta contra a exclusão de modo mais abrangente e também contraditório. Abria-se, também a possibilidade de confrontos e o delineamento de novos pontos de vista, em função das diferenças culturais e identitárias que afetavam a todos, inclusive os ex internos. Um breve relato da gestora italiana do Centro Diurno "Il Girasole" ilustra esta potência (Gramantieri, 1995). Segundo ela, ocorria um encontro entre pessoas "diversas" que tinham em comum o fato de serem "estranhas - estrangeiras". Para os usuários o encontro intercontinental "foi uma espécie de iluminação". Ela citou uma situação ilustrativa, ocorrida no interior do pavilhão 4 de um dos manicômios, quando, com outras pessoas, presenciou a condução de uma atividade com os pacientes:

\begin{abstract}
Em uma tarde fazíamos um jogo que era conduzido por uma educadora brasileira, de nome Lúcia, que nessa época ainda não falava muito bem o italiano. Nesse jogo, ela tentava estimular as pessoas a jogar a bola, de um para o outro, e então dizia: "Joga a bala para Mario". Nem "bola" em português, nem "palla" no italiano, mas um pouco de cada um.
\end{abstract}

As pessoas se entendiam, superavam as barreiras linguísticas e culturais, pois havia uma situação de curiosidade. Assim como as brasileiras, os usuários também eram diversos e existia tanta estranheza que deviam encontrar-se, mesmo porque naquela época haviam poucos estrangeiros em uma pequena cidade como Ímola; era uma raridade e isto despertava uma forte curiosidade para os usuários: as brasileiras falavam do Natal no Brasil "com suas toalhas cheias de cerejas, seus modos de vida, suas culturas, tudo gerava muito interesse por parte deles". Havia uma grande atenção e, inclusive, um usuário em particular mostrou que "sabia mais sobre o Brasil que qualquer pessoa de Ímola". Se criava assim uma situação de enriquecimento de conhecimento, pois os ex-internos viveram tantos anos confinados no manicômio e agora se descortinava para eles "um mundo muito amplo, muito maior que Ímola, que era um mundo pequeno, limitado".

Tudo isso permitia, também a flexibilização da burocracia institucional: ignorada e questionada pelos estrangeiros. Por outro lado, essas diferenças também geravam conflitos. Mas, é interessante observar que se abriram possibilidades de coordenação, pesquisa e formação. Isso sinaliza uma posição que não é periférica, do ponto de vista profissional, ainda que a formação das terapeutas ocupacionais e psicólogas não tenham sido reconhecidas formalmente, dificultando a integração. Os desafios relativos às dificuldades de comunicação (precária expressão no idioma estrangeiro), ao preconceito e à estigmatização também foram recorrentes, especialmente para as brasileiras. Todas estas dificuldades se convertiam em tensão e stress quando se 
tratava de questionar as condições de trabalho e o alcance dos projetos de reinserção, como, por exemplo, no caso do trabalho com equipes reduzidas ou na avaliação de projetos personalizados mal efetivados. Foram sinalizadas nas entrevistas com os brasileiros e brasileiras que, ao longo do tempo e após o fechamento dos manicômios, o apoio e o financiamento aos processos de inclusão se fragilizaram.

A abertura e capacidade inventiva eram fortemente estimuladas, a ponto de comportar a possibilidade de que brasileiras "vivessem" na primeira residência, junto aos ex internos. Nestes espaços de inserção era necessário usar a criatividade para não reproduzir o isolamento manicomial.

A versatilidade dos estrangeiros, descomprometidos com os limites normativos da cultura manicomial, geravam inquietação produtiva, assim como se expunham a grande, as vezes excessiva, multiplicidade de tarefas: nas residências se fazia de tudo. O compromisso político com a desinstitucionalização era um elemento fundamental, assim como os laços informais de amizade e a construção de possibilidades expressivas em festas, encontros: fazendo arte, no sentido amplo. Arriscava-se a construção de espaços de convivência, como ocorria, por exemplo, no "Il Girasole": atividades manuais, ou simplesmente tomar "um chá juntos e conversando, criando assim um espaço diferente dos espaços do manicômio", assim como passear, viajar, visitar parentes dos usuários, promover festas, feiras com os produtos feitos no centro diurno "e tantas outras iniciativas". É relevante recorrer aqui ao relato da psicóloga que trabalhou no "Il Girasole" (Lucimar). Ela se lembrou de um usuário que, quando o Centro Diurno ainda funcionava no manicômio, vinha sempre, de manhã:

... se sentava no banco em frente ao Girasole e não aceitava o nosso convite para entrar. Os enfermeiros diziam que ele não conversava, ou seja, era capaz de pronunciar apenas poucas palavras. Começamos sentando do lado dele e ele sempre perguntava que dia era. Daí tivemos a ideia de convidá-lo para trocar as datas em um calendário que elaboramos especialmente para ele. A princípio ele entrava somente para trocar a data do calendário e saia em seguida. Aos poucos ele começou a interessar-se pelo que os outros usuários faziam e em pouco tempo pegou um pincel e começou a pintar. De vez enquanto nós o acompanhávamos até o bar do manicômio para tomar um café, pois era uma das poucas coisas que ele conseguia expressar o seu prazer, [...]. Depois de algum tempo de idas e vindas ao bar do manicômio eu o convidei para ir tomar um café fora do hospital e o convite foi aceito, apesar do medo que ele tinha de sair. Na rua ele agarrou no meu braço e repetia sem parar que iriamos só tomar um café fora e imediatamente voltaríamos para dentro [do manicômio]. O trabalho com ele foi longo e insistente, mas o resultado foi maravilhoso. Depois de algum tempo ele saia sozinho do manicômio, caminhava por toda a cidade e aquele "Lobo solitário" que vivia trancado dentro dos muros do manicômio ganhou 
vida, espaço, voz e uma grande simpatia, pois ele ficou conhecido em toda a cidade.

Tratava-se de uma construção conjunta, emocionada, que implicava também na inserção dos brasileiros e brasileiras. Ainda que houvessem dificuldades sistemáticas, as entrevistas sinalizaram a plena participação nas assembleias, no coletivismo criativo, na produção de espaços para a construção de autonomia e exercício de escolha. O trabalho em equipe também tinha centralidade, abrindo as possibilidades dialógicas.

Nas entrevistas com os italianos que trabalharam com os brasileiros surgem expressões importantes, que qualificavam a presença brasileira: leveza, abertura mental, afetividade, contato físico, naturalidade, alegria.

Para Ennio Sergio, psicólogo do Centro de Saúde Mental imolense, os brasileiros eram pessoas que não faziam pesar o fato de ter uma formação acadêmica com seus conhecimentos teóricos: "Eles estavam ali para adquirir novos conhecimentos", disse em entrevista. Segundo ele,

... eram pessoas que tinham uma postura autêntica, que valorizavam a atenção com o outro, com sua história, que davam importância a dimensão paritária nas relações. Mostravam uma abertura em relação ao novo, em vivenciar o direito de cidadania com os usuários, dispostos a romper barreiras, a superar limites, romper os muros institucionais.

\section{Tempero brasileiro: um sabor estrangeiro}

Os testemunhos recolhidos nos permitem tirar algumas considerações sobre o impacto que os brasileiros tiveram sobre a transformação institucional do manicômio de Ímola, nos nove anos durante os quais começa e termina o processo que define o encerramento total do manicômio. É um período particularmente intenso, durante o qual passamos de uma tradição anterior e consolidada de cerca de dois séculos, para outra totalmente nova, que assiste à derrubada das absurdas regras asilares, a abertura libertadora para fora e além dos muros do Lolli e do Osservanza, o envolvimento de novos protagonistas, o estabelecimento de novas organizações associações, cooperativas, residências, centro diurno e outros dispositivos.

Foi um fervor criativo, quase frenético, dominado pela impaciência revolucionária. O tempo irrompe na vida cotidiana: os ponteiros dos relógios, bloqueados pelas teias de aranha do passado, foram rapidamente movidos para o presente. A subjetividade dos internados, anteriormente presos no engessamento do diagnóstico, manifesta-se em toda a sua dolorosa poética, que denuncia a repressão passada e vivida. 
As mudanças são medidas pela abertura de novos espaços para inclusão social, mas acima de tudo por uma nova maneira de pensar, de fazer, de ser, para com aqueles que foram vítimas da instituição e para aqueles que, ao longo do tempo, não viram (ou fingiram não ver) essa injustiça. Os brasileiros e brasileiras aqui citados estão neste processo, ou melhor, precisamente, no centro desse processo. Certamente nos referimos aos "visitantes" e que, naqueles anos, ecoavam a reforma no Brasil: pessoas que trabalham no Ministério da Saúde brasileiro, ou em outras instituições importantes de ensino e pesquisa (como a Fundação Oswaldo Cruz), professores universitários ou funcionários que desempenham papéis importantes na saúde pública. Seu tempo de permanência pode ser longo, se eles faziam uma pesquisa universitária, ou um doutorado ou se participam de um curso (como aquele feito pela Organização Mundial da Saúde). Ou, então, o tempo podia ser relativamente breve. Mas é sempre uma presença importante: ela contribui para o intercâmbio de experiências, entrelaça novos relacionamentos, abre várias possibilidades, enriquece o clima de atenção que a cidade reverbera no processo de desinstitucionalização, dando a esse processo um crédito adicional.

Mas os brasileiros que estão no centro da nossa pesquisa são outros - aqueles que foram chamamos de "os voluntários", e desempenham um papel real, fundamental e específico. São jovens que trabalharam nas novas instalações do departamento de saúde mental imolense e que escolheram viver por meses e anos, na cidade de Ímola. Estamos falando dos protagonistas deste artigo. Deles, nos afeta o "gap" entre os resultados lisonjeiros de sua presença - leveza, abertura mental, afetividade, contato físico, naturalidade, alegria - descrito pelos italianos, e a fragilidade do papel profissional desempenhado nestas circunstâncias. Então, quem são esses jovens brasileiros e brasileiras? Eles são um pequeno número de pessoas que não se movem pela ambição de carreira universitária ou política e que não estão respaldados por nenhum acordo institucional formalizado que garantisse uma continuidade de trabalho no retorno ao Brasil. Eles vêm, quase acidentalmente, mas profundamente motivados apenas pelo desejo de uma experiência existencial válida, forte, transformadora. Por estes motivos e pela falta de uma lei italiana que permita regulamentar legalmente o seu trabalho, essas pessoas estão expostas a uma vida cotidiana difícil, à incerteza e à precariedade. Apesar desses obstáculos, que enfrentam com coragem, seu impacto no processo de desinstitucionalização é notável, superando todas as expectativas iniciais da pesquisa. Esta consideração exige-nos algumas perguntas. De onde vem o seu impacto no processo de desinstitucionalização? De qual conhecimento, capacidade ou competência são enunciadores? Existe uma especificidade em ser "estrangeiro"? Brasileiros, em particular? Uma primeira reflexão diz respeito precisamente à suposta "brasilianidade" e nos traz uma consideração 
cultural, que pode parecer, a primeira vista, estereotipada. Há, no seu comportamento, um calor, uma vitalidade na relação, que é diferente dos demais profissionais de Ímola, que trabalhavam no processo de desinstitucionalização. Em quase todos os depoimentos dos imolenses, foi reconhecido esse "valor agregado". Está indicado nas atividades, nas festas, no carnaval, promovido pelos brasileiros: é uma energia calorosa, que agita positivamente a inércia dos pacientes e da cidade. A comunicação proxêmica dos brasileiros é completamente diferente daquela dos operadores de Ímola. Nestes últimos, prevalece a distância física (ainda que respeitosa), a formalidade na comunicação. Os brasileiros, em vez disso, buscam a proximidade, o contato físico. Impressiona - como Nicoletta Gramantieri, gestora do "Il Girasole" reconheceu: o posicionar-se facilmente, para "massagear", por exemplo, os corpos dos pacientes, o tratamento informal, o expor-se de maneira direta, o "jogar-se" imediatamente no uso de uma linguagem desconhecida, a vontade impaciente de superar todas as dificuldades (neste caso linguística) que podem dividir as pessoas. Pode-se dizer - tentando limitar os riscos de uma retórica excessiva - que os brasileiros aumentam sua capacidade de promover reabilitação, devido às suas peculiaridades culturais.

Mas para responder as perguntas que fizemos na conclusão deste artigo, parece importante concentrar nossa atenção em um problema, que emerge das entrevistas: as discussões que, em várias ocasiões, opuseram os brasileiros aos enfermeiros, em relação ao trabalho a ser feito, tanto no interior do hospital como nas residências. É indiscutível que ocorreu, pelo menos em um estágio inicial, significativa dificuldade por parte de alguns enfermeiros para aceitar as grandes mudanças que se impunham.

As entrevistas denotam, em vez disso, um mundo outro ("estrangeiro") à lógica do asilo. Os funcionários da instituição e os brasileiros têm uma visão de pessoas e coisas completamente diferentes. Como nas imagens usadas para descrever a teoria da Gestalt, alguns veem os vasos no primeiro plano, outros os dois perfis que se encaixam. O olhar do funcionário público, quando burocratizado, confirma-se na impossibilidade de uma mudança, talvez para não ver a violência de que ele é vítima e executor: seu olhar é "opaco", expressão de uma "falsa consciência". O olhar das e das brasileiras e brasileiros comparáveis àquele da criança, descrita pelo poeta e escritor Hans Christian Andersen, no conto do "A roupa nova do Rei", que pode detectar a nudez, os paradoxos e as inconsistências; um olhar que, pela sua experiência de "estranheza", identifica a relatividade de cada "conhecimento", de cada ato. Mas é também o olhar que sabe reconhecer a ampla gama de possibilidades dos pacientes. Essa habilidade é compreensível se considerarmos as outras características do grupo de pessoas enfocado, além da característica "estrangeira": são portadores de uma formação em terapia ocupacional, psicologia, são expressão de um 
profissionalismo desconhecido na Itália, e, em alguns casos, não eram sequer profissionais de uma área médico-sanitária prevalente nas profissões de terapeutas italianos. Estas são características que, contra o pensamento comum, acabam se transformando em oportunidades, e não, limites. Por quê? Talvez porque a consciência da limitação estimule a criatividade na busca de uma solução.

Naturalmente, o elemento mais importante para a possibilidade de mudança reside no poder da motivação. Neste caso, os jovens brasileiros optaram por realizar uma experiência existencial, baseada em uma motivação ético-política radical. A afirmação dos direitos da pessoa derrubou o conhecimento baseado na pseudociência manicomial, que negou esses direitos.

Para esquematizar esses conceitos, tentando torná-los mais compreensíveis, nos referiremos a um artigo (Venturini, 2016, pag.170), que usa linguagem metafórica para descrever as principais características da desinstitucionalização, abordando os temas de um livro famoso de Ítalo Calvino (1988). Estas características são, no texto de Calvino e no artigo, a "leveza", a "rapidez", a "exatidão", a "visibilidade", a "multiplicidade". Apontando, então, como uma referência, esses indicadores, podemos examinar a prática de operadores sociais brasileiros e dos funcionários institucionais de Ímola.

É destacado, brevemente, que: o olhar dos brasileiros é delicado, criativo (leveza), o dos oficiais é pesado, monótono; as ações dos brasileiros estão prontas para responder às necessidades dos usuários (rapidez), os funcionários são geralmente caracterizados pela inércia; os brasileiros respondem prontamente e rigorosamente às necessidades dos usuários (exatidão), os funcionários referem-se a esquemas de totalização (conceito de doença mental), a protocolos abstratos; os brasileiros trazem, com seu trabalho na vida cotidiana, o "dentro" para "fora" e viceversa, evidenciam o porquê dos comportamentos (visibilidade); os funcionários, em vez disso, deixavam as contradições dentro dos muros do asilo; os brasileiros referem-se às histórias complexas de pessoas (multiplicidade), os funcionários reduzem as contradições da realidade ao diagnóstico.

Através desta simplificação esquemática, pode ser entendida a diversidade de olhares (e ações) entre os dois grupos. Os brasileiros e as brasileiras parecem corresponder, com todas as contradições presentes em um processo tão complexo, às características necessárias para operar na desinstitucionalização. Os trabalhadores do hospital psiquiátrico de Ímola têm mais dificuldade em separar-se da identidade institucional que os aprisionou há anos.

Basicamente, parece-nos que as duas qualidades peculiares, que dão um valor agregado ao trabalho dos brasileiros em Ímola, são a estranheza à lógica abrangente e fagocitante da instituição, como resultado provável de uma militância política e 
social realizada anteriormente no Brasil e também pelo simples fato de ser "estrangeiro" que lhes possibilita o lugar do estranhamento e sua potência crítica. De certa forma, tanto para os usuários do antigo asilo quanto para os trabalhadores de Ímola e para os entrevistados e entrevistadas, é realizado aquele encontro com o Outro, que Emmanuel Levinas (2001) chama de "evento fundamental", o da mais importante experiência da vida, que abre aos horizontes mais elevados. O encontro entre o eu, o você, o Outro (um Outro com um O maiúsculo, como Levinas define) destaca as diferenças únicas e inacessíveis entre indivíduos, os preserva da massificação e do totalitarismo institucional, destruidores de cada identidade individual.

O reconhecimento do Outro, como diz Levinas, é de importância decisiva: eleva e salva os seres humanos, ajuda a nos colocar em um nível de igualdade, na diferença, e a manter um diálogo aberto.

Em nossa linguagem comum, "estrangeiro" é muitas vezes caracterizado por termos negativos, porque alude aquilo que os indivíduos designados não são (não ser originais do nosso país), alude ao não ter (a nossa língua, cultura, religião), à serem portadores de uma exterioridade desprovida de qualquer conotação, exceto a da estranheza. O efeito semântico desta representação é a obscuridade de todas as diferenças entre as múltiplas identidades linguísticas, culturais e religiosas das quais a humanidade é constituída. O anonimato se reflete no relacionamento tornando-o impessoal: decisivo não é o que nos une, mas o que nos divide.

No mundo grego de Eurípides, Esquilo, nos poemas homéricos, em Platão, em vez disso, a figura do estranho é positiva: muitas vezes é a de um deus que assume a forma humana. Esta possibilidade promove as leis da hospitalidade. Xenos (estrangeiro) é aquele que se beneficia das leis da hospitalidade. A benevolência é necessária para ele, porque está sozinho, sem companheiros e familiares. A hospitalidade não significa a assimilação: xenos é sagrado, precisamente porque é outra coisa e irredutível.

O encontro com o Outro, o encontro com diferentes seres humanos, sempre representou a experiência fundamental e universal de nossa espécie. O que aconteceu em Ímola nos fala da recorrente descoberta que cada um de nós faz ao longo da vida: o encontro com o Outro.

O Outro, neste caso, é o brasileiro, é a brasileira, mas é também o é o "doente mental" para o supostamente "saudável" (e vice-versa). Ao tomar essa consciência, entendemos que a reabilitação das pessoas com sofrimento ou distúrbio mental consiste na recuperação desta dimensão positiva de "alteridade", através do "simples" reconhecimento dos direitos de cidadania (Levinas, Peperzak \& Charamelli, 2001). Assim a reabilitação real do paciente pode ser a reabilitação também de todos que 
participam do processo (os terapeutas, os educadores, os operadores do campo da saúde mental, neste caso).

Tzvetan Todorov (1992), nos lembra que todos estamos envolvidos nesta questão, porque o estrangeiro não é - não só é - o nosso próximo, mas é o que pode acontecer a nós mesmos, por causa de um destino incerto: cada um de nós é estrangeiro em potencial (possibilidade). Devemos sempre ir além do nosso ponto de vista subjetivo e tentar assumir o dos outros. Isso aparece como resultado do dialético encontro, que foi realizado em Ímola entre diferentes "estrangeiros", no cenário privilegiado da desinstitucionalização.

\section{De volta para casa: Xenos - o insuportável}

Destas experiências de vida e trabalho, resultaram diversos destinos. Alguns retornaram ao Brasil e outros, poucos, continuaram atuando na área de saúde mental.

Anna, depois, de Ímola foi para Trieste e trabalhou por muitos anos como funcionária em uma cooperativa, na área de Saúde Mental. Participou da experiência de desinstitucionalização do hospital psiquiátrico na ilha de Leros (Grécia). Voltou no Brasil e hoje trabalha em uma ONG ligada à saúde mental em Brasília. Lucia voltou para o Brasil em 1994 e depois seguiu para os Estados Unidos (cidade de Memphis), trabalhando como terapeuta ocupacional em uma instituição para pessoas com deficiência múltipla, em um projeto de desinstitucionalização que resultou na constituição de residências. Depois disso, voltou para o Brasil e hoje trabalha em Campinas. Ademir retornou a sua cidade natal, Itu no interior de São Paulo, e continuou o trabalho intensamente em um Centro de Atenção Psicossocial para infância e adolescência. Edison rumou para a cidade de Jundiaí no interior de São Paulo, trabalhando como artista e artesão, e, mantendo suas raízes e experiência, ele vende seus produtos em uma lojinha junto a um restaurante italiano. Lucimar, continuou vivendo na Itália, complementando sua formação em psicologia, mas trabalhando como artesã e colaborando com a pesquisa cujo resultado estamos compartilhando. Luciene, também continuou na Itália, sem vínculos com a psiquiatria e trabalhando como artesã. Adriana vive em Florianópolis e trabalha como tradutora autônoma tendo retornado à Itália para fazer um doutorado em Estudos da Tradução.

\section{O que fica de toda esta história?}

Pouco ... muito. Os brasileiros seguiram caminhos diferentes da vida, como deveria ser.

Os tempos mudaram. Surgiram outros problemas, outras formas de marginalização. 
Ennio Sergio comentou que, se ocorresse hoje, a experiência dos brasileiros, ela se colocaria no interior de uma moldura que não permitiria a expressão da criatividade, do novo, sendo provavelmente coibidos dentro de diretrizes preestabelecidas. "Se bate em uma porta hoje, vai encontrar alguém que reproduz os seus poderes e isto é o contrário do que ocorria no processo de desinstitucionalização onde se discutia a redistribuição de poderes, ou o confronto de poderes". Naquela época, "existia uma atmosfera onde todos podiam expressar a própria ideia e isto era visto como enriquecedor". Ele informou que, atualmente, no departamento de saúde mental de Ímola, não existem mais os mesmos profissionais, a gerência mudou, e os conhecimentos técnicos tendem a ser reproduzidos rigidamente.

Mas, naturalmente, permanece a conquista daquele objetivo: o manicômio foi definitivamente derrubado, destruído. Permanece também o testemunho do sucesso de uma luta de grande empenho, onde se destacou a coragem de jovens estrangeiros que conseguiram atravessar o oceano e se expor a muitas dificuldades, por motivos ideais, solidários aos revolucionários italianos dos anos noventa.

Permanece esta história, com seus limites e contradições ... Não é uma coisa pequena.

No clássico livro Mil e Uma Noites é contada a história do rei Shariar, que, por causa da traição de sua esposa, dirige sua vingança contra toda mulher jovem, seduzida e morta por ele no início de cada novo dia. Porém Sherazade, a filha do vizir de Chahzeman, interrompe esse ritual ao fazer com que o rei se apaixone por suas mil histórias, conquistando assim o seu amor. Sherazade nos ensina, através da literatura, que o relato é vida, é um baluarte contra a morte. Ela inventa o próprio princípio da narrativa (relato sem fim, criação de laços e tramas, descoberta de significados). Seduz o déspota sanguinário, transformando-o. Ela não ataca diretamente, demonstra inteligência e indica, a quem deve enfrentar o poder, o caminho da libertação: a invenção contínua e a ruptura dos esquemas. O processo de mudança ativado em Ímola, com a ajuda de um grupo de jovens brasileiros (e também italianos e de outras nacionalidades) foi um acontecimento que tem seu lugar na história invisibilizada, em trânsitos, estrangeiros, em caminhos inusitados. Tal processo criou confiança, reciprocidade. A retomada destes relatos, como na fábula de Sherazade, nos afasta da metáfora da morte, que nos é imposta pelas instituições da violência e pela sombra do esquecimento, que negam os direitos das pessoas à existência.

Todas histórias de libertação e de trânsito no mundo - assim como esta pequena história - são formas de reapropriação da vida, para os oprimidos e em cada um de nós. 


\section{Referências}

Calvino, I. (1988). Lezioni Americane. Milano: Garzanti.

De Platô, G. \& Venturini, E. (2000). La promoción de la Salud Mental. Bologna: Regione Emilia-Romagna Press.

Ferreira, G. (1996). De Volta Pra Casa: pratica de reabilitação com pacientes crônicos em Saúde Mental. Em A. M. F. Pitta (Org.). Reabilitação Psicossocial no Brasil (pp. 80-88). São Paulo: Hucitec.

Galassi, N. (1989). Diece secoli di storia ospedaliera a Imola. Ímola: Galeati.

Gaskell, G. (2002). Entrevistas individuais e grupais. Em M. W. Bauer \& G. Gaskell. Pesquisa qualitativa com texto, imagem e som - um manual prático (pp. 64-89). Petrópolis: Vozes.

Giacanelli, F., Iachini, S. \& Migani, C. (1994). L'assistenza psichiatrica a Imola in epoca pontificia. Em E. Venturini. La città proibita (pp. 14-16). Imola: AzUSL.

Goulart, M. S. B. (2004). De profissionais a militantes: a luta antimanicomial de psiquiatras italianos nos anos 60 e 70. Tese de Doutorado, Programa de PósGraduação em Ciências Humanas: Sociologia e Política, Universidade Federal de Minas Gerais.

Goulart, M. S. B. (2006). A Construção da Mudança nas Instituições Sociais: $A$ Reforma Psiquiátrica. Pesquisas e Práticas Psicossociais, 1, p.1-19.

Goulart, M. S. B., Venturini, E., Baliero, H. G., \& Chaves, A. L. F. (2015). La presenza storica dei brasiliani nella pratica della salute mentale di Trieste:"Venite a Vedere" o Fare Insieme?. Fogli d'Informazione 35/36, Luglio-dicembre2015, Ass. Epidauri, Firenze.

Lancetti, A. \& Amarante, P. (2013). Saúde Mental e Saúde Coletiva. Em G. W. Campos. Tratado de Saúde Coletiva (pp. 661-680). São Paulo: Hucitec.

Levinas. E., Peperzak, A. \& Ciaramelli, F. (2001). (a cura di). Etica come filosofia prima. Milano: Guerini e Associati.

Migani, C. (1994). La nascità dell'impresa manicomiale imolese dal 1862 al primo decennio del Novecento. Em E. Venturini. La città proibita (pp. 16-21). Imola: AzUSL.

Todorov, T. (1992). La conquista dell'America. Torino: Einaudi. 
Venturini, E. (2016). A Linha Curva - o espaço e o tempo da desinstitucionalização. Rio de Janeiro: Editora Fiocruz.

Venturini, E., Degano, L. \& Gramantieri, N. (1995). La malattia del vento - uno sbocco possibile alla cronicità. Rimini: Guaraldi.

\section{Nota sobre os autores}

Maria Stella Brandão Goulart é doutora em Ciências Humanas: Sociologia e Política pelo Departamento de Sociologia da Faculdade de Filosofia e Ciências Humanas da Universidade Federal de Minas Gerais. É professora-associada do Departamento de Psicologia da Faculdade de Filosofia e Ciências Humanas da Universidade Federal de Minas Gerais. E-mail: goulartstella2011@gmail.com.

Ernesto Venturini é mestre em Administração e Gestão de Serviços Sanitários para Dirigentes de Aziende Sanitarie Saude pela Universidade de Bologna. Psiquiatria Democrática Italiana. Azienda Sanitaria di Imola, Fondazione Franca e Franco Basaglia. E-mail: eventurini250@gmail.com.

Adelaide Lucimar Fonseca Chaves é psicóloga clínica. Especialista em Psicologia Transformacional (Azienda de Saúde de Nápoles) e em Psico-oncologia (Azienda de Saúde de Bologna). E-mail: lufonseca@libero.it.

Data de recebimento: $25 / 01 / 2019$

Data de aceite: 20/02/2020 